\begin{tabular}{|c|c|}
\hline Title & $\begin{array}{l}\text { Social factors enhancing foraging success of a wild group of Japanese macaques (Macaca fuscata) in a patchy food } \\
\text { environment }\end{array}$ \\
\hline Author(s) & Kazahari, Nobuko; A getsuma, Naoki \\
\hline Citation & $\begin{array}{l}\text { Behaviour, 145(6), 843-860 } \\
\text { https://doi.org/10.1163/156853908783929188 }\end{array}$ \\
\hline Issue Date & 2008 \\
\hline Doc URL & http:/hdl. handle.net/2115/51736 \\
\hline Type & article (author version) \\
\hline File Information & Kazahari \& A getsuma (2008).pdf \\
\hline
\end{tabular}

Instructions for use 
Behaviour 145: 843-860.

\title{
Social factors enhancing foraging success of a wild group of Japanese macaques (Macaca fuscata) in a patchy food environment
}

\author{
Nobuko Kazahari1) \& Naoki Agetsuma²) \\ ( ${ }^{1}$ Graduate School of Environmental Science, Hokkaido University, Sapporo, Japan; ${ }^{2}$ Field Science Center for Northern \\ Biosphere, Hokkaido University, Sapporo, Japan) \\ (Accepted: 11 December 2007)
}

\begin{abstract}
Summary
We evaluated the effects of social factors and food quality on patch use by a wild group of Japanese macaques (Macaca fuscata) that experienced no inter-group feeding competition or predation risk. We obtained the following results: (1) Food patch depletion and within-group scramble competition for food apparently did not affect patch use. (2) Within-group contest competition (aggressive interactions related to social-dominance rank) also did not strongly affect patch use. (3) The number of co-feeders in the same patch consistently showed positive effects on patch use, while food quality did not have consistent effects. These results suggest that the presence of co-feeders enhances foraging success in a patchy food environment. Keywords: food competition, group foraging, intake speed, patch quality, patch use, social facilitation.
\end{abstract}

\section{Introduction}

Studies of animal foraging behaviors have often assumed that foragers adopt optimal foraging strategies to maximize energy intake (e.g., Stephens \& Krebs, 1986). Many models of optimal patch use have been proposed to explain the foraging strategies of animals that depend on patchily distributed resources (e.g., Charnov, 1976; Iwasa et al., 1981). These models assume that the forager decides when to leave a food patch based on the decline in intake 3) speed (number of items eaten per unit of time) caused by patch depletion. The marginal value theorem (MVT: Charnov, 1976) has become the base of many other patchuse models (e.g., Stephens \& Krebs, 1986). This theory predicts that (1) a forager stays longer to feed in higher quality patches, (2) a forager continues to feed in each patch until temporal intake speed falls to a fixed "marginal value" for the given food condition and (3) a forager stays longer in each patch as the overall food condition becomes poorer in the habitat. The MVT has successfully explained patch use by various species (e.g., in birds: Krebs et al., 1974; Cowie, 1977; Kacelnik, 1984; in insects: SchmidHempel et al., 1985; in primates: Agetsuma, 1998).

Many primates living in forests feed on patchily distributed fruits and leaves (Leighton \& Leighton, 1982; Nakagawa, 1989a; Agetsuma, 1995a), and the predictions of the MVT have been tested for several primate species in the wild. For example, Whitten (1988) found that vervet monkeys (Cercopithecus aethiops) tended to stay longer in higher quality patches that allowed for higher intake speed. Barton \& Whiten (1994) also reported longer patch residence times in larger food patches by 
anubis baboons (Papio anubis). These studies support the predictions of the MVT. However, some other primate species tend to leave food patches without a decrease in intake speed through patch depletion (e.g., Japanese macaque, Macaca fuscata: Nakagawa, 1990; Lar gibbon, Hylobates lar, and Siamang, $H$. syndactylus: Grether et al., 1992). Those researchers have suggested that some social factors may influence patch use in these group foragers. In fact, Japanese macaques foraging behavior followed the predictions of the MVT, when various social factors were experimentally excluded (Agetsuma, 1999). However, very little is known of the effects of social factors on patch use.

The presence of other individuals induces feeding competition. The foraging success of group-living primates tends to decrease through indirect competition for food by other group members (scramble competition: Janson \& van Schaik, 1988) and direct competition for food by aggressive interactions and dominance rank (contest competition: Janson \& van Schaik, 1988). However, van Schaik (1989) pointed out that individuals are not free to go anywhere to avoid food competition among the group members and must stay within certain range. It might be because most primate species have strong social bonds among group members. Group members frequently exchanged social behaviors (social grooming: Goosen, 1981, vocal communication: Wang, 2000; Sugiura, 2007) and keep proximity to one another even in foraging (Pastor-Nieto, 2001). Then, individuals often leave food patches to follow other group members or gave up patches due to aggressive behavior by dominant individuals (Nakagawa, 1990). Thus, to understand patch uses by group-living primates, it is necessary to consider the effects of social factors, such as dominance rank and presence of group members sharing the same food patches simultaneously (co-feeders).

In Japanese macaques, females remain in the natal troops throughout their lives and mature males migrate between troops. The macaques have a linear dominance hierarchy between females, which is nepotistic, that is, a daughter is ranked after her mother (Kawamura, 1965). The rank order also exists between kin groups (Koyama, 1970). The macaques feed mainly on fruits, seeds, flowers, and leaves according to the availability of these food resources (Nakagawa, 1989b; Agetsuma, 1995b). Under poor food conditions associated with the winter season, severe competition for food might arise (Saito, 1996). Therefore, this species is an appropriate subject for detecting social effects on food patch use. We examined patch use by Japanese macaques in a wild group in relation to social factors as well as patch quality, testing the following predictions. (1) As the patch use models predict, in the course of foraging, food availability will decrease, and, in turn, food intake speed will also decrease. In addition, if there are co-feeders intake speed will decrease faster as a result of scramble competition. (2) If contest feeding competition is apparent, aggressive interactions will affect patch use. This tendency should be much more apparent among lower ranking individuals. (3) Patch quality will have positive effects on food patch use, while social factors (dominance rank and co-feeders) will have negative effects on food patch use in the patches as a result of feeding competition. 


\section{Material and methods}

Study site and subjects

The study site, Kinkazan Island (10 km2), is located in northern Japan (38

covered with a mixed forest of coniferous and broadleaved trees (Yoshii \& Yoshioka, 1949), and resident macaques have no predators (Izawa, 1983).

During the study periods, six groups of Japanese macaques were living on the island, with a total population size ranging from 217 to 230 individuals (Izawa, 2005). These macaques feed mainly on leaves and flowers in spring and on seeds and fruits of several woody plants in autumn (Izawa, 2004). Trees are sparse because of the high feeding pressure by sika deer (Yoshii \& Yoshioka, 1949); thus, each food tree can be defined as a food patch (Nakagawa, 1990). The B1 group was selected for observation of foraging behavior. There were three periods of observation covering two seasons, spring (April-May 2003 and May-June 2004) and autumn (September-October 2003). The troop ranges mainly throughout the central part of the island from the seaside to the island peak (445 m above sea level; Izawa, 1999). During the study, the group consisted of 11-12 adult females (7 years old and older), 1-2 adult males ( 7 years old and older), 2-3 young females (5-6 years old), 2-4 juveniles (1-4 years old) and 2-3 infants. We determined dyadic dominance relationships between adult females and a linear dominance hierarchy using the Dominance Directed Tree Method (Izar et al., 2006) as follows. First, the dominance relationship between each pair of adult females was decided based on the number of victories in agonistic interactions. Second, unknown relationship was resolved applying the transitiveness property (i.e., if $A$ is dominant to $B$ and $B$ is dominant to $C$, then $A$ is dominant to $C$ ). The adult females were divided into three dominance rank classes (high, middle, and low), each of which comprised three or four females. We chose two females from each class (i.e., six in total) in spring and Autumn 2003, and one female from each class (i.e., three in total) in Spring 2004, for observations of feeding behavior. These females had no infants during the observation seasons.

Patch use

In this study, we analyzed four aspects of patch use: residence time in each food patch (tree), percentage of time spent feeding, intake speed, and amount of food items consumed in each patch. We followed one female each day from dawn to dusk with as few interruptions as possible. We recorded the time of entrance into and departure from each food patch to obtain the residence time in the patch. Behavioral data were collected by the focal animal sampling method (Altmann, 1974), in which we recorded observed behaviors of the focal animal for every 8-min session. For the first 5 min of the observation session (behavior sampling sub-session), we recorded the duration of behaviors of the focal animal in seconds. When the focal female stayed in the food patch, we recorded the food type (species and part) and classified her behaviors into three categories: (1) feeding: eating food items, including 
handling, processing, and chewing; (2) searching: moving and searching for food; and (3) inactive: resting, self-grooming and social-grooming. When the focal female was feeding, we also recorded the number of food items eaten and time spent feeding on them as few missing as possible, to estimate the intake speed in each session. In addition, we recorded aggressive behaviors directed at focal females by

other group members (e.g., being attacked and replaced by other individuals approaching within $1 \mathrm{~m}$ ) in food patches by ad libitum sampling (Altmann, 1974) during the behavior sampling sub-session. In the last 3 min of an observation session (co-feeder sampling sub-session), we counted the number of group members in the same food patch with the focal female. These animals were assumed to be co-feeders.

We followed each focal animal for 4 to 5 days in each season, for a total of $195 \mathrm{~h}$ in April-May 2003, $181 \mathrm{~h}$ in September-October 2003 and $121 \mathrm{~h}$ in May-June 2004. On average we recorded 75 sessions per observation day. When focal animals stayed in food patches, we observed their behaviors for $86.2 \%$ of the total time of the behavior sampling sub-sessions. The percentage of time spent feeding in each session was estimated by dividing the time spent feeding by the observation time of the behavior sampling sub-session. Intake speed in each session was calculated by dividing the observed number of food items eaten by the time spent feeding on that number of items in each behavior sampling subsession. The amount of food items consumed in a visit to each food patch was estimated by multiplications of the mean intake speed, mean percentage of time spent feeding in each session and residence time in each patch.

Patch quality

All food types used by focal animals more than 10 times in each season, excluding the flower of Berberis thunbergii, were selected for analysis. These plants were the flower and seed of Fagus crenata (fl-FC and se-FC), leaf and seed of Zelkova serrata (lf-ZS and se-ZS), fruit of Comus brachypoda (fr-CB), flower of Pourthiaea villosa (fl-PV) and fruit of Prunus $x$ yedeoesis (fr-PY). We surveyed the patch size, density of food items in the tree crown, and number of proximate patches of food trees used by focal animals to determine the patch quality. For estimation of the food patch size, we measured the height of tree crowns and the maximum and minimum crown widths. We then estimated the patch size of each tree as the volume of an elliptic cylinder, calculated using the maximum and minimum widths as the major and minor axes, respectively, and the height. The density of food items in each food patch was also recorded $(<0.25,0.25-0.5,0.5-0.75$ and $>0.75$ of the crown; see Whitten, 1988) when focal animals visited the patch. The locations of all food trees used by focal animals throughout each observation season were plotted on a map. The maximum extent of group dispersion was approximately within a radius of $50 \mathrm{~m}$ during foraging (personal observation). Therefore, food patches within $50 \mathrm{~m}$ of the focal animal were assumed to be alternative food resources for the animal at that time. We counted the number of proximate patches during every visit to food patches in each season. 
Data analysis

Nutritional contents may differ among food types in the study area (Nakagawa, 1997). In addition, food densities in patches are not comparable among food types. Therefore, we analyzed food patch uses separately for each food type.

\section{Patch depletion and scramble feeding competition (prediction 1)}

We examined whether intake speed decreased with time spent in patches. If the patch becomes depleted, intake speed will decline with the time spent in patches (i.e., session order). However, intake speed may also decrease when the animal is satiated by a food item (Nakagawa, 1990). Therefore, decrease of intake speed does not always reflect patch depletion. The more co-feeders stay in the patch, the sooner intake speed will decrease by scramble competition leading to patch depletion. If a patch then becomes depleted, the number of co-feeders and interaction between the session order and number of co-feeders should have negative effects on intake speed for each session. We examined the effects of session order, number of co-feeders, and their interaction on intake speed using a generalized linear mixed model (GLMM, using the glmmML package of the statistical software R.2.5.0; http://www.rproject. org/). Each patch visit was designated as a random effect in the model. The best model was determined by removing independent variables that did not improve Akaike's information criterion (AIC) compared to that for the full models. Table 1 lists other information on the model.

\begin{tabular}{|c|c|c|c|c|c|c|}
\hline \multicolumn{2}{|c|}{ Prediction Dependent variables } & \multirow{2}{*}{$\begin{array}{l}\text { Independent variables } \\
\text { Session order. } \\
\text { number of co-feeders } \\
\text { session order } \times \text { number of co-feeders }\end{array}$} & \multirow{2}{*}{$\begin{array}{l}\text { Model } \\
\text { GLMM }\end{array}$} & \multirow{2}{*}{$\frac{\text { Offset }}{\text { log( time spent feeding.) }}$} & \multirow{2}{*}{$\begin{array}{c}\text { Error distribution } \\
\text { Poisson }\end{array}$} & \multirow{2}{*}{$\begin{array}{c}\text { Link function } \\
\log \end{array}$} \\
\hline (1) & Intake speed (number of food items eaten) & & & & & \\
\hline (2) & $\begin{array}{l}\text { Frequency of aggressive behavior } \\
\text { (occurrences of aggression in each patch) }\end{array}$ & Dominance rank & GLM & $\log ($ total obsevation time in patch) & Poisson & $\log$ \\
\hline (3) & $\begin{array}{l}\text { Percentage of time spent feeding } \\
\text { (time spent feeding ) } \\
\text { Intake speed (number of food items eaten) } \\
\text { Residence time }\end{array}$ & $\begin{array}{l}\text { Social factors } \\
\text { - (dominance rank, number of co-feeders) }\end{array}$ & GLM & $\begin{array}{c}\log (\text { obsevation time in session) } \\
- \\
-\end{array}$ & $\begin{array}{c}\text { gamma } \\
-\frac{\text { Poisson }}{\text { gamma }}-- \\
-\frac{-\frac{-}{\text { Poisson }}--}{}\end{array}$ & $\begin{array}{c}\log \\
--\frac{\log }{\log }-- \\
--\frac{\log }{\log }---\end{array}$ \\
\hline
\end{tabular}

\section{Contest feeding competition (prediction 2)}

Aggressive behaviors by dominant individuals may lead to decreased feeding time and intake speed because foragers must pay attention to the dominant individuals or abandon their feeding spots. Moreover, foragers may even give up food patches. As a result, the amount of food items consumed in the food patches may decrease. Such negative effects of contest feeding competition are more apparent in lower-ranking individuals (Saito, 1996; Vogel, 2005). We tested the negative effects on the percentage of time spent feeding and intake speed in each session, and the residence time and total amount of food 
items consumed in each patch.

Males often attacked females during the mating season (September and October 2003). Such attacks may be different from feeding competition, although the attacks may affect foraging behaviors. Thus, for this study we only analyzed aggressive behaviors by other females. We observed only 18 cases of such aggressive behaviors during $48 \mathrm{~h}$ of total observation time for the behavior sampling sub-sessions. Using Mann-Whitney U-tests, we compared the percentage of time spent feeding and intake speed in sessions, residence time and total amount of food items consumed in each patch with and without aggressive behaviors for food types observed three or more cases of aggressive interactions (i.e., se-FC, If-ZS, and $\mathrm{fl}-\mathrm{PV}$ ).We also tested the relationship between dominance rank and the frequency of aggressive behaviors using a generalized linear model (GLM, using R.2.5.; Table 1). The significance of the factors was estimated by the GLM with quasi-Poisson error against overdispersion. All food types were analyzed together because of the small number of cases.

\section{Effects of social factors and food conditions on patch use (prediction 3)}

Dominant females may have negative effects on the foraging behaviors of subordinates, regardless of the apparent social interactions. Subordinates may abandon better feeding spots or give up a food patch to avoid dominants before interactions. We quantified the effects of social factors (dominance rank and number of co-feeders) as well as patch quality (patch size, density of food items and number of proximate patches) for each aspect of patch use (intake speed and percentage of time spent feeding for each session; residence time and amount of food consumed in each patch) using the GLM (Table 1). For intake speed and the amount of food items consumed in each patch, the significance of each factor was estimated by the GLM based on quasi-Poisson error against over-dispersion.

Results

Patch depletion and scramble feeding competition (prediction 1)

We predicted that if patch depletion occurred in the course of the patch use, intake speed would decrease, and the speed would decrease faster with co-feeders as result of scramble competition. Then, we analyzed the effects of time spent in patches (i.e., session order), the number of co-feeders and their interaction on intake speed.

Table 2. Selected variables affecting intake speed of each food item by GLMM

\begin{tabular}{|c|c|c|c|c|c|c|c|c|c|c|c|c|c|c|}
\hline \multirow[b]{2}{*}{ Variables } & \multicolumn{2}{|c|}{$\mathrm{fl}-\mathrm{FC}(N=96)$} & \multicolumn{2}{|c|}{ se-FC $(N=128)$} & \multicolumn{2}{|c|}{ If-ZS $(N=201)$} & \multicolumn{2}{|c|}{ se-ZS $(N=110)$} & \multicolumn{2}{|c|}{$\mathrm{fr}-\mathrm{CB}(N=43)$} & \multicolumn{2}{|c|}{ fl-PV $(N=59)$} & \multicolumn{2}{|c|}{$\mathrm{fr}-\mathrm{PY}(N=25)$} \\
\hline & Estimate & SE & Estimate & SE & Estimate & SE & Estimate & SE & Estimate & SE & Estimate & SE & Estimate & SE \\
\hline $\begin{array}{l}\text { Intercept } \\
\end{array}$ & "-0.700 & 0.171 & $-1.595^{\text {twt }}$ & 0.043 & "-0.912 & 0.021 & -0.689 & 0.005 & $2-0.601$ & 0.115 & $-1.014^{\text {ttm }}$ & 0.068 & -1.100 & 0.112 \\
\hline Session order & -0.031 & 0.006 & & & & & & & -0.153 & 0.038 & & & & \\
\hline Number of co-feeders & & & & & $-0.009^{*}$ & 0.004 & -0.015 & 0.008 & & & $0.093^{*}$ & 0.033 & & \\
\hline Session order $\times$ Number of co-feeders & $0.001^{\star}$ & 0.001 & & & & & 0.003 & 0.001 & & & -0.014 & 0.009 & -0.024 & 0.005 \\
\hline
\end{tabular}


Session order was selected as a negative factor for two of seven food types (fl-FC, fr-CB; Table 2). However, for both types, the number of co-feeders and the interaction between the session order and number of co-feeders showed no negative effects on intake speed. While the number of co-feeders had negative effects on intake speed for If-ZS and se-ZS, session order and interaction between the session order and the number of co-feeders did not have negative effects. These results suggest that apparent patch depletion and scramble competition did not occur during our observation periods.

\section{Contest feeding competition (prediction 2)}

We observed 18 cases of aggression from other females in food patches (2 cases/19 patch visits for flFC; $3 / 56$ for se-FC; 5/40 for fl-ZS; 0/29 for se-ZS; $2 / 27$ for fr-CB; $6 / 35$ for fl-PV; and 0/11 for fr-PY). The frequency of aggressive behaviors in food patches was, thus, relatively low (0.375 occurrences/h on average). We tested the effect of aggressive behaviors on patch use in three food types (se-FC, If-ZS and fl-PV) to examine contest competition. The percentage of time spent feeding in the sessions with aggressive behaviors decreased significantly for If-ZS, but not for the other two food types (Table 3). Intake speed in the sessions was not significantly decreased by aggressive behaviors for all three food types. Residence time and amount of food consumed in each patch also did not decrease significantly with aggressive behaviors for all three food types. Dominance rank was not selected by the GLM as a factor affecting the frequency of receiving aggressive behavior $(N=216$, intercept $=-9.11, S E=0.37, p$ $<0.001)$. Therefore, the frequency of aggressive behavior by other females was not determined by the dominance rank.

Above all, aggressive behaviors did not show important negative effects on patch use. In addition, lower-ranking females did not frequently receive aggressive behaviors from other females. These results indicate that contest competition for foods, which we had predicted, was not readily apparent.

Table 3. Summary for Mann-WhitneyU-tests of patch use in relation to interference's occurrence.

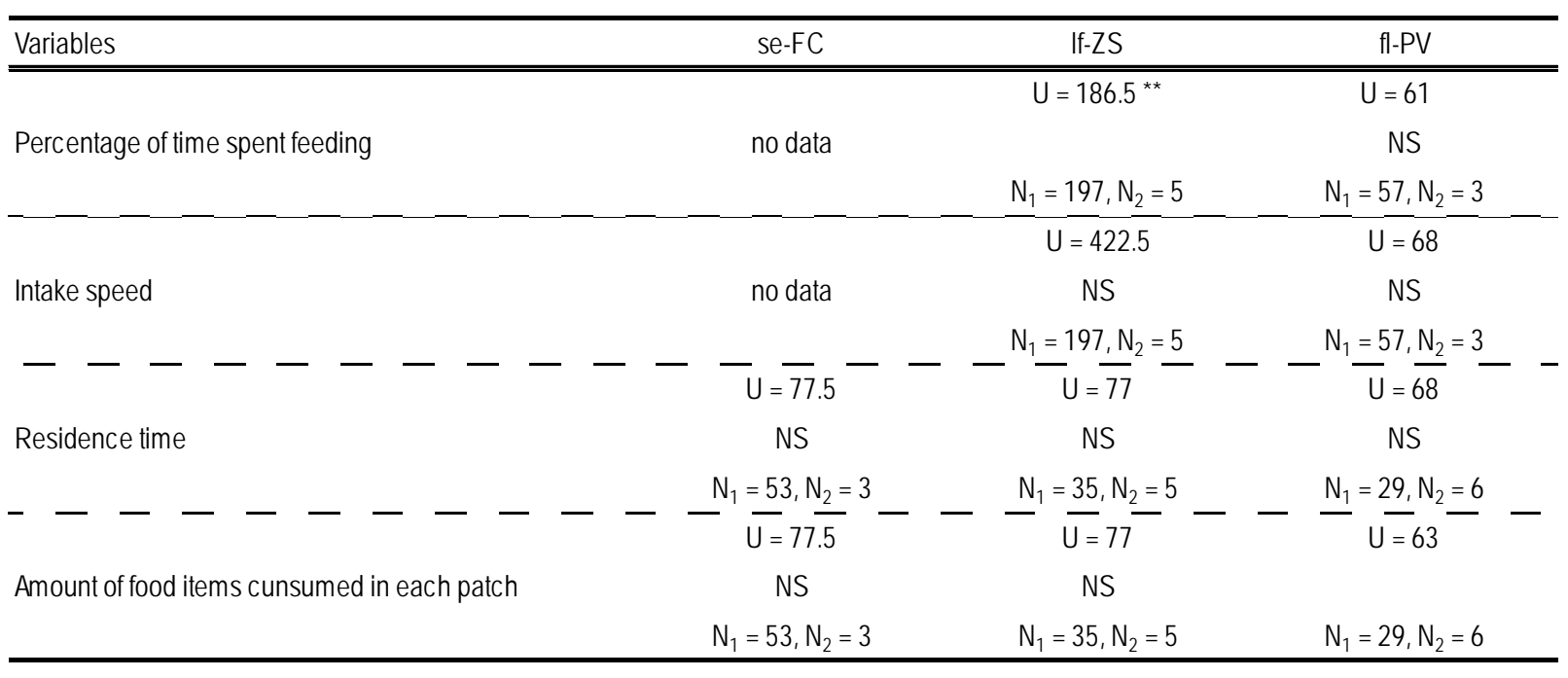

${ }^{*} p<0.05,{ }^{* *} p<0.01,{ }^{* * *} p<0.001$ 


\section{Effects of social factors and food conditions on patch use (prediction 3)}

The effects of social factors, as well as food patch quality, on patch use were tested by GLM. The GLM selected different variables for patch use by food types (Table 4). The patch size and density of a food item did not always have positive effects on patch use. The number of proximate patches also did not have consistent effects on intake speed and percentage of time spent feeding in each session or on the amount of food items consumed in each food patch. However, the number of proximate patches did have a negative effect on residence time for the three food types. Effects of dominance rank differed among food types. Thus, patch quality and dominance rank did not have consistent effects on patch use by these macaques.

However, the number of co-feeders had positive effects on many aspects of patch use, excluding the percentage of time spent feeding (Table 4). The number of co-feeders increased (or did not decrease) the intake speed and residence time for all food types. In addition, for six of seven types, the amount of food consumed in each patch increased with the number of co-feeders.

Thus, the number of co-feeders had consistent positive effects, while patch quality did not have consistent effects on patch use, against our prediction. The positive effect of social factor means that certain social facilitations may act on their food patch use.

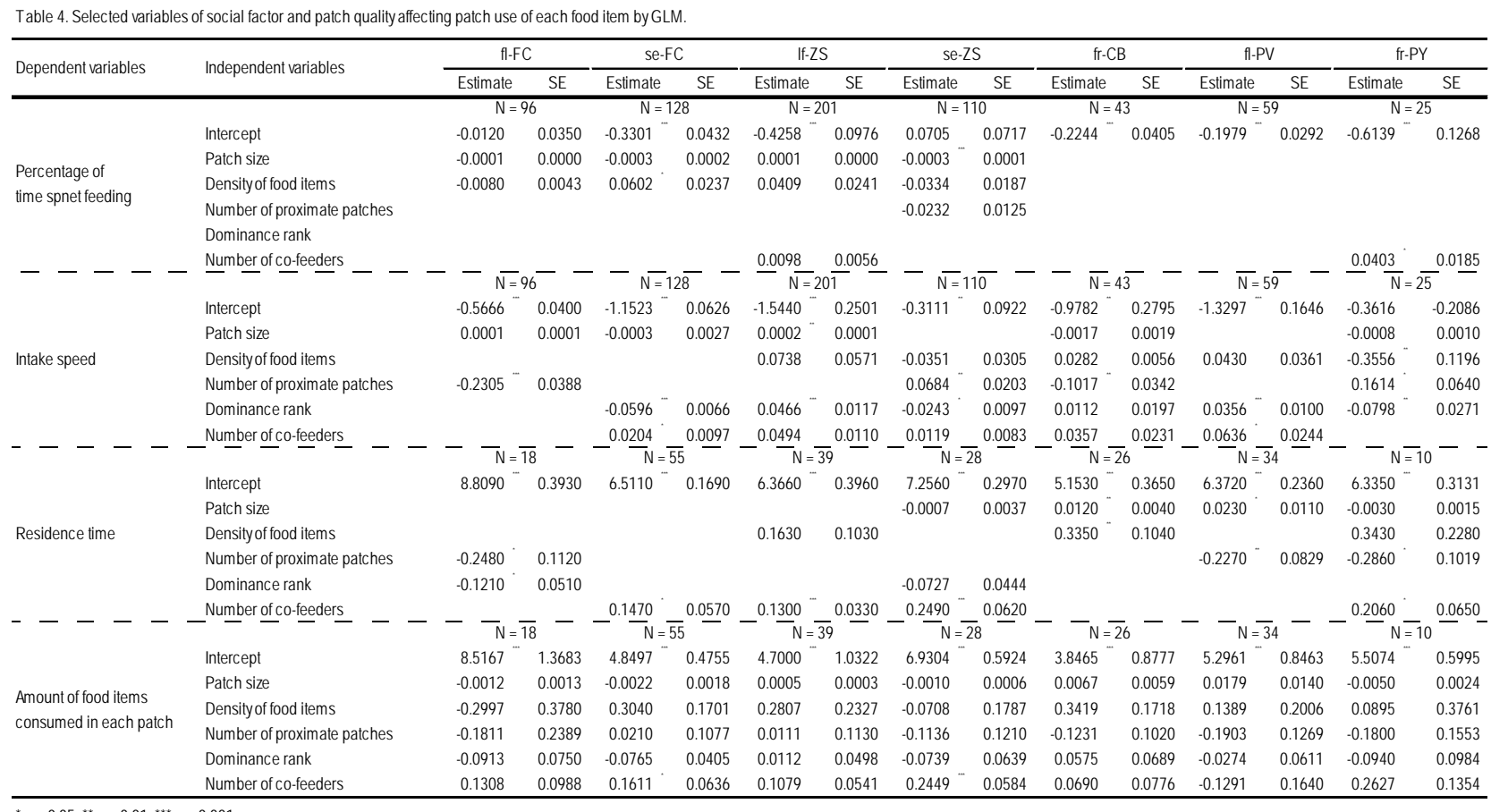

${ }^{*} p<0.05,{ }^{* *} p<0.01,{ }^{* * *} p<0.001$

\section{Discussion}

Previous studies on group-living primates have suggested that other group members have negative 
effects on foraging efficiency through food competition (Janson, 1988; Janson \& van Schaik, 1988; Barton, 1993; Barton \& Whiten, 1993). However, in this study such negative effects (within-group scramble and contest competition) were not detected clearly. Rather, the presence of group members in the same food patches showed consistently positive effects on the patch use. Thus, the presence of group members improved foraging success through some undetermined mechanisms.

Patch depletion and scramble feeding competition (prediction 1)

Previous studies have suggested that the foraging success of group-living primates tends to decrease through scramble competition (Janson \& van Schaik, 1988). However, in this study apparent food patch depletion was not shown, and then scramble competition could not have been strong.

If scramble competition occurs in food patches, the time spent in food patches, number of co-feeders, and their interaction will all have negative effects on intake speed in the food patch. That is, the more cofeeders stay in the patch, the sooner the intake speed will decrease by scramble competition, leading to patch depletion. However, if only the passage time shows negative effects, the patch may not be depleted because the forager may leave the patch for other reasons, such as satiation with the food items (Nakagawa, 1990). In our study, for two of seven food types, time spent in food patches (i.e., session order) had negative effects on intake speed (Table 2). However, the number of co-feeders and the interaction between session order and the number of co-feeders did not negatively affect intake speed. These results suggest that there was still sufficient food in the patches so as not to decrease intake speed or cause scramble food competition.

\section{Contest feeding competition (prediction 2)}

Several studies have documented the relationship between foraging success and aggressive behaviors for food (within-group contest competition: Janson, 1988; Barton, 1993; Barton \& Whiten, 1993). These studies have suggested that contest competition tends to decrease foraging success in lowerranking individuals. However, in our study group the contest competition for food was not severe.

In our study, aggressive behaviors relating to food competition by dominant individuals (Wrangham, 1980; Oliver, 2003) were rarely observed. The percentage of time spent feeding in sessions with aggressive behaviors did not decrease significantly for se-FC and fl-PV (Table 3). For If-ZS, the percentage of time spent feeding was significantly lower in sessions with aggressive behaviors. However, there was no significant difference between sessions before and after the aggressive behavior in a patch use. Intake speed was not significantly different between sessions with and without aggressive behaviors for the three food types (Table 3) or between sessions before and after the aggressive behaviors for If-ZS. Residence time was not affected by aggressive behaviors (Table 3). As a result, the amount of food items consumed in the patches also did not decrease by aggressive behaviors (Table 3). These results 
suggest that aggressive behaviors from dominant females did not have important negative effects on patch use. In addition, lower-ranking females were not frequently involved in interferences from other females. Therefore, contest competition for foods was not readily apparent.

\section{Effects of social factors and food conditions on patch use (prediction 3)}

Patch quality and dominance rank did not have consistent effects on patch uses (Table 4). The inconsistent effects of patch quality and dominance rank may be because food items in each patch were relatively abundant, and then food competition would not have been severe during the study seasons. However, Saito (1996) pointed out that strong feeding competition does occur for high-quality but small and isolated food patches in the study area. Similar analyses will be required under poor food conditions to confirm the effects of these factors on foraging behavior.

On the other hand, the number of co-feeders showed consistent positive effects on intake speed, residence time, and the amount of food consumed in each patch for most food types. This result suggests that there were certain positive effects of co-feeders on patch use.

\section{Social factors enhancing foraging success}

In our study, we could not detect clear negative effects of social factors on patch use through scramble and contest competitions suggested by previous studies (e.g., Grand \& Dill, 1999; Snaith \& Chapman, 2005; Vogel, 2005). Instead, our results show that the presence of other group members in the same food patches had consistent positive effects on foraging success. Previous studies have suggested that the presence of other individuals is beneficial for foraging when inter-group competition is severe (Wrangham, 1980; Janson \& van Schaik, 1988) and when predation pressure is high (Berger, 1978; Caraco, 1979; Sullivan, 1984). However, in our study area, macaques have no predators (Izawa, 1983) and inter-group encounters occur infrequently (Saito et al., 1998). In fact, there was no interaction with neighboring groups during the study seasons (personal observation). Nevertheless, for most food types, co-feeders had positive effects on food patch use (Table 4). Below, we present three possible mechanisms of enhanced foraging success.

(1) Response to potential competition. When food is scarce, sharing food with other individuals will lead to rapid depletion of food resources. In such a situation, foragers should increase food intake speed as much as possible. Thus, the response can be adaptable to scramble competition for food. Even if food is abundant, the presence of other individuals may stimulate foragers to raise their intake speed.

(2) Social facilitation. Humans tend to increase the amount of food eaten in a meal as the number of co-feeders increases (de Castro \& Brewer, 1992). Higher intake speed is especially apparent when eating with a spouse and family (de Castro, 1994). Capuchin monkeys under laboratory conditions also ate more food per unit time when other individuals were eating than when others were not eating 
(Galloway et al., 2005). Similar social facilitation may occur in wild Japanese macaques.

(3) Prevention of straying. van Schaik (1989) pointed out that group members must stay within a certain range relative to other group members so as not to lose their group. When only a few monkeys are in the same patch, individuals must pay more attention to locations of other members and may give up the patch to stay in contact with others. In contrast, when many members are in the same patch, individuals can concentrate more on foraging because there is a lower probability of losing track of the others. In this study, we found that co-feeders had positive effects on foraging success even under conditions of low inter-group competition and low predation risk. This could be one of the benefits of group living. Further studies are needed to confirm the social enhancement of feeding behaviors in other gregarious species.

\section{Acknowledgements}

Prof. K. Izawa of Teikyo University of Science and Technology offered valuable help and information on the study site, and Ms. Y. Sugiura helped identify individuals within the study group. Staff of the Kinkazan Koganeyama Shrine and members of the Field Work jointstudy room of Miyagi University of Education provided hospitality and assistance during the fieldwork. Prof. T. Kubo of Hokkaido University helped with the statistical analyses. We also greatly appreciate fruitful discussions regarding data analysis with Prof. M. Murakami, Hokkaido University, Dr. K. Tanaka, Sheffield University, Prof. G. Takimoto, Toho University, and staff and researchers at the Tomakomai Experimental Forest (TOEF). This study was partially financed by the Cooperative Research Fund of the Primates Research Institute, Kyoto University, to N. K.

\section{References}

Agetsuma, N. (1995a). Foraging strategies of Yakushima macaques (Macaca fuscata yakui). - Int. J. Primatol. 16: 595-609.

Agetsuma, N. (1995b). Dietary selection by Yakushima macaques (Macaca fuscata yakui): the influence of food availability and temperature. -Int. J. Primatol. 16: 611-627.

Agetsuma, N. (1998). Simulation of patch use by monkeys using operant conditioning. — J. Ethol. 16: 49-55.

Altmann, J. (1974). Observational study of behaviour: sampling method. — Behaviour 49: 227-267.

Barton, R.A. (1993). Sociospatial mechanisms of feeding competition in female olive baboons, Papio anubis.- Anim. Behav. 46: 791-802.

Barton, R.A. \& Whiten, A. (1993). Feeding competition among female olive baboons (Papio anubis).- Anim. Behav. 46: 777789.

Barton, R.A. \& Whiten, A. (1994). Reducing complex diets to simple rules: food selection by olive baboons. —Behav. Ecol. Sociobiol. 35: 283-293.

Berger, J. (1978). Group size, foraging, and antipredator ploys: an analysis of bighorn sheep decisions. - Behav. Ecol. Sociobiol. 4: 91-99. 
Caraco, T. (1979). Time budgeting and group size: a theory. — Ecology 60: 611-617.

de Castro, J.M. (1994). Family and friends produce greater social facilitation of food intake than other companions. — Physiol. Behav. 56: 445-455.

de Castro, J.M. \& Brewer, E.M. (1992). The amount eaten in meals by humans is a power function of the number of people present.-Pyhsiol. Behav. 51: 121-125.

Charnov, E.L. (1976). Optimal foraging, the marginal value theorem. — Theor. Pop. Biol. 9: 129-136.

Cowie, R.J. (1977). Optimal foraging in great tits (Parus major). - Nature 268: 137-139.

Galloway, A.T., Addessi, E., Fragaszy, D.M. \& Visalberghi, E. (2005). Social facilitation of eating familiar food in tufted capuchins (Cebus apella): does it involve behavioral coordination? -Int. J. Primatol. 26: 181-189.

Goosen, C. (1981). On the function of allogrooming in Old-World monkeys. - In: Primate behaviour and sociobiology (Chiarelli, A.B. \& Corruccni, R.S., eds). Springer, Berlin, pp. 110-120.

Grand, T.C. \& Dill, L.M. (1999). The effect of group size on the foraging behaviour of juvenile coho salmon: reduction of predation risk or increased competition? - Anim. Behav. 58: 443-451.

Grether, G.F., Palombit, R.A. \& Rodman, P.S. (1992). Gibbon foraging decisions and the marginal value model. -Int. J. Primatol. 13: 1-17.

Iwasa, Y., Higashi, M. \& Yamamura, N. (1981). Prey distribution as a factor determining the choice of optimal foraging strategy.-Am. Nat. 117: 710-723.

Izar, P., Ferreira, R.G. \& Sato, T. (2006). Describing the organization of dominance relationships by dominance-directed tree method. —Am. J. Primatol. 68: 189-207.

Izawa, K. (1983). The ecological study of wild Japanese monkeys living in Kinkazan Island, Miyagi Prefecture.- Bull. Miyagi Univ. Educ. 18: 24-45.

Izawa, K. (1999). A comparison of six monkey troops on Kinkazan Island. — Japanese Monkeys in Miyagi Prefecture 10: 1-11.

Izawa, K. (2004). Food list of Japanese monkeys in Kinkazan Island: a revised edition. -Japanese Monkeys in Miyagi Prefecture 18: 1-16.

Izawa, K. (2005). Population changes of Japanese monkeys in Kinkazan Island. — Japanese Monkeys in Miyagi Prefecture 19: 1-10.

Janson, C.H. (1988). Food competition in brown capuchin monkeys (Cebus paella): quantitative effects of group size and tree productivity. -Behaviour 105: 53-76.

Janson, C.H. \& van Schaik, C.P. (1988). Recognizing the many faces of primate food competition: methods.- Behaviour 105: 165-186.

Kacelnik, A. (1984). Central place foraging in starlings (Sturnus vulgaris). 1. Patch residence time. -J. Anim. Ecol. 53: 283-299.

Kawamura, S. (1965).Matriarchial social ranks in theMinoo-B group: a study on rank system of Japanese macaques. - In: Japanese monkeys (Imanishi, K. \& Altmann, S.A., eds). Emory University Press, Atlanta, GA, pp. 87-104.

Koyama, N. (1970). Changes in dominance rank and division of a wild Japanese troop monkey in Arashiyama.-Primates 11: 335-390.

Krebs, J.R., Ryan, J.C. \& Charnov, E.L. (1974). Hunting by expectation or optimal foraging? A study of patch use by chickadees. 
-Anim. Behav. 22: 953-964.

Leighton, M. \& Leighton, D.R. (1982). The relationship of size of feeding aggregate to size of food patch: howler monkeys (Alouatta palliata) feeding in Trichilia cipo fruit trees on Barro Colorado Island.-Biotropica 14: 81-90.

Nakagawa, N. (1989a). Bioenergetics of Japanese monkeys (Macaca fuscata) on Kinkazan Island during winter._Primates 30: 441-460.

Nakagawa, N. (1989b). Feeding strategies of Japanese monkeys against deterioration of habitat quality. — Primates 30: 1-16.

Nakagawa, N. (1990). Decision on time allocation to different food patches by Japanese monkeys (Macaca fuscata). —Primates 31: 459-468.

Nakagawa, N. (1997). Determinants of the dramatic seasonal changes in the intake of energy and protein by Japanese monkeys in a cool temperate forest. - Am. J. Primatol. 41: 267-288.

Pastor-Nieto, R. (2001). Grooming, Kinship, and co-feeding in captive spider monkeys (Ateles geoffroyi). — Zoo Biol. 20: 293303.

Saito, C. (1996). Dominance and feeding success in female Japanese macaques, Macaca fuscata: effects of patch size and inter-patch distance. - Anim. Behav. 51: 967-980.

Saito, C., Sato, S., Suzuki, S., Sugiura, H., Agetsuma, N., Takahata, Y., Sasaki, C., Takahashi, H., Tanaka, T. \& Yamagiwa, J. (1998). Aggressive intergroup encounters in two populations of Japanese macaques (Macaca fuscata). — Primates 39: 303-312.

van Schaik, C.P. (1989). The ecology of social relationships amongst female primates. - In: Comparative socioecology (Standen, V. \& Foley, R.A., eds). Blackwell Scientific, London, pp. 195-218.

Schmid-Hempel, P., Kacelnik, A. \& Houston, A.I. (1985). Honeybees maximize efficiency by not filling their crop. —Behav. Ecol. Sociobiol. 17: 61-66.

Schülke, O. (2003). To breed or not to breed-food competition and other factors involved in female breeding decisions in the pair-living nocturnal fork-marked lemur (Phaner furcifer). - Behav. Ecol. Sociobiol. 55: 11-21.

Snaith, T.V. \& Chapman, C.A. (2005). Towards an ecological solution to the folivore paradox: patch depletion as an indicator of within-group scramble competition in red colobus monkeys (Piliocolobus tephroscseles).- Behav. Ecol. Sociobiol. 59: 185-190.

Stephens, D.W. \& Krebs, J.R. (1986). Foraging theory.-Princeton University Press, Princeton, NJ.

Sugiura, H. (2007). Adjustment of temporal call usage during vocal exchange of coo call in Japanese macaques.- Ethology 113: 528-533.

Sullivan, K.A. (1984). The advantages of social foraging in downy woodpeckers. - Anim. Behav. 32: 16-22.

Vogel, E.R. (2005). Rank differences in energy intake rates in white-faced capuchin monkeys, Cebus capucinus: the effects of contest competition.-Behav. Ecol. Sociobiol. 58: 333-344.

Wang, X. (2000). On cortical coding of vocal communication sounds in primates. — Proc. Natl. Acad. Sci. USA 97: 11843-11849.

Whitten, P.L. (1988). Effects of patch quality and feeding subgroup size on feeding success in vervet monkeys (Cercopithecus aethiops). - Behaviour 105: 35-52.

Wrangham, R.W. (1980). An ecological model of female-bonded primate groups. — Behaviour 75: 262-300. 
Yoshii, Y. \& Yoshioka, K. (1949). Plant communities of Kinkazan Island. — Ecol. Rev. Sendai 12: 84-105. 